\title{
Telecommuting for Business Continuity in a Non-profit Environment
}

\author{
Teh Boon Heng ${ }^{1}$, Soh Chin Hooi ${ }^{1}$, Yan Yap Liang ${ }^{1}$, Azizie Othma ${ }^{1} \&$ Ong Tze San ${ }^{2}$ \\ ${ }^{1}$ Faculty of Management, Multimedia University, Cyberjaya, Malaysia \\ ${ }^{2}$ Faculty of Economics and Management, University Putra Malaysia, Serdang, Malaysia \\ Correspondence: Teh Boon Heng, Faculty of Management, Multimedia University, Cyberjaya, Malaysia. E-mail: \\ bhteh@mmu.edu.my
}

Received: May 17, 2012 Accepted: June 21, 2012 Online Published: September 20, 2012

doi:10.5539/ass.v8n12p226

URL: http://dx.doi.org/10.5539/ass.v8n12p226

\begin{abstract}
The recent event of global pandemic outbreak, natural disaster, terrorist attacks and extreme climate changes have highlighted the importance of putting in place a business continuity management (BCM) planning. One of the known branches of BCM is telecommuting.

The project implementation was based on a non-profit environment context. Due to the practical manner of the project, canonical action research was chosen as the method of study. The methodology is essentially divided into 3 cyclical phases, problem diagnosis, intervention, evaluation. The purpose of this study is to document step by step telecommuting design and implementation. Towards the end of the study evaluation of the whole project design and implementation was performed. This was done to discover lessons learned as well as to evaluate the $\mathrm{BCM}$ readiness of the organization and understanding the level of participant motivation towards telecommuting.
\end{abstract}

Keywords: telecommuting, business continuity management, non-profit environment, action research, canonical action research, Malaysia

\section{Introduction}

\subsection{Setting an Agenda}

It is inevitable that Information Technology (IT) is playing a pivotal role to enable business to perform their day to day transactions and this becomes a much more crucial factor as the size of the establishment grows. Natural disasters, terrorist attacks and pandemic are stories often becoming a headline in news today. The mentioned events happen globally around the world. With that in mind, risk mitigation plans are an important aspect to be thoroughly analyzed for IT implementation. Business Continuity Planning is an area of expertise whose objective is to plan and implement risk mitigating procedures to ensure business processes which are vital for an organization are still running to minimize any form of transactional "down-time" in a time of an emergency. The Hemagglutinin 1 Neuraminidase 1 (H1N1) global pandemic was announced on 11th July 2009 as reported by BBC. As was reported by the Star Newspaper on 21st June 2009 the first school in Malaysia was closed as to avoid the propagation of the virus. This could also be seen as a possibility for business premises to be closed which will result in transaction interruption. Another recent example would be harsh winter conditions which occurred in Brussels, United Kingdom (UK) in January 2010 which resulted in disruption in travel as a Eurostar train broke down. This was reported by the Daily Mail UK. The scenario could be anticipated from this were employees being unable to commute to their work place. How should an organization respond to such events? Telecommuting is one of the approaches adopted more and more widely by the business community to deal with such events.

\subsection{Scope of Studies}

The study will concentrate on Non-profit organization as limited research conducted in this area nevertheless non-profit organization such as school and hospital are equally important compare to profit organization.

\subsection{Research Questions}

1) What are the steps necessary in implementation of a business continuity planning in a non-profit organization?

2) What are the outcome and lessons learned from the telecommuting implementation in a non-profit organization? 


\subsection{Research Objectives}

1) Design and implement telecommuting as a business continuity planning in a non-profit organization.

2) Analyze the telecommuting implementation in a non-profit organization which includes:

a. Examine employee perceived benefit of telecommuting in a non-profit organization.

b. Examine organization business continuity management readiness as perceived by telecommuting participants.

\section{Literature Review}

\subsection{Business Continuity Management (BCM)}

Business Continuity Management is defined by the Business Continuity Institute (BCI) as:

"A holistic process that identifies potential threats to an organization and the impacts to business operations that those threats, if realized might cause. It provides a framework for building organizational resilience with the capability for an effective response that safeguards the interests of key stake holders, reputation and brand and value-creating activities." - Good Practice Guidelines (2010, p. 3).

The organization will review the potential risks it faces and keep a register of the identified risks and produce a variety of scenarios of disruption to the business. It is important to note here, that scenarios are not only highlighting catastrophic or extreme disasters, but also account for more minor incidents and occurrences which might results in disruption to the business. Next would be the assessment of the impact of risk to the business. BCM is not meant to be used on every single service in the organization, by doing so it only enforces the lack of clarity in assessing critical activities. Management teams from different department need to sit down together and provide input and feedback to the whole BCM discussion. For instance every department needs to list down services that are critical to the organization and determine the criticality of the service in a given scenario. This in turn ensures that identified risks and services are truly critical instead of having BCM implemented on every single service in the organization.

Clear et al (2005) in his article mentioned that, risk is a negative outcome which has a known or estimated chance of taking place. The knowledge of this comes from either past occurrence or conducted studies. This clearly specifies the need to identify and analyze risk. BCM is a framework put into place to deal with internal scenarios such as system failures of Buncefield oil explosion, Buncefield Investigation, (2005). Also external scenarios for example terrorist attacks of London bombing as reported by BBC (2005) and World Trade Center Attack, BBC (2001), natural disaster, Haiti earthquake 2010, BBC (2010), and H1N1 pandemic, announced by WHO (2009).

\subsection{Telecommuting a BCM Approach}

One approach for a BCM is "telecommuting" also referred to "telework" in literature. Telecommuting is defined by Webopedia based on Jack Niles reference as a means for an employee to connect and transfer data as well as documents to the main office from a remote location (generally from home) through the use of a telephone line. Back during the days when this idea had just been introduced, the cost involved in implementing telecommuting was a major concern as with the available technology at the time. Organizations which were able to afford implementing such facility were mainly well funded organizations, such as the military and space research agencies. Today however most of these technologies are available at an affordable price. Moreover, the advancement in technology since has made telecommuting infrastructure robust and user friendly. One example that we can see today are the use of Blackberry devices as a medium of communication for keeping oneself connected to the workplace. The device not only allows users to make calls and send text message through the use of Short Message Service (SMS) it also enables the sending and receiving e-mails as a cost effective alternative. Being able to manage e-mails at your fingertip anywhere and anytime provides a more complete communication experience.

Telecommuting is for its most part tied to the policy and governance of human resources of an organization. However as pointed out by Siemens in a white paper entitled "Get Lean and Green Fast (2009)" published by Siemens it was stated that a telecommuting project of different concept shares two common characteristics, which are:

1) The spread of employees in geographical location. Employees are able to connect remotely and perform their duties anywhere as long as the mean of connectivity exist (internet access). 
2) Employees access to organization's systems. This includes but not limited to communications, database, ERP, e-mails and applications.

\subsection{Catalyst for Telecommuting}

In the literature by Gilyot, Zhang, Alijani, and Thangada (2004) catalyst for the adoption of telecommuting were analyzed. The study was conducted based on the comparison in the United States. It was mentioned that the higher level of education of a society the more evident the use of telecommuting initiative will be. Thus this suggests that there is a relationship between the level of knowledge of technology and the adoption of telecommuting. Another factor which was considered as a strong indicator of the adoption rate of telecommuting adoption came from the economical perspective. A state with stronger economy was also found to have higher rate of adoption of telecommuting. It was also indicated that in a situation where commuting to the workplace is a challenge; the levels of telecommuting adoption were higher. Figure 1 illustrates the model being used by the writer to study factors which increased the level of telecommuting adoption.

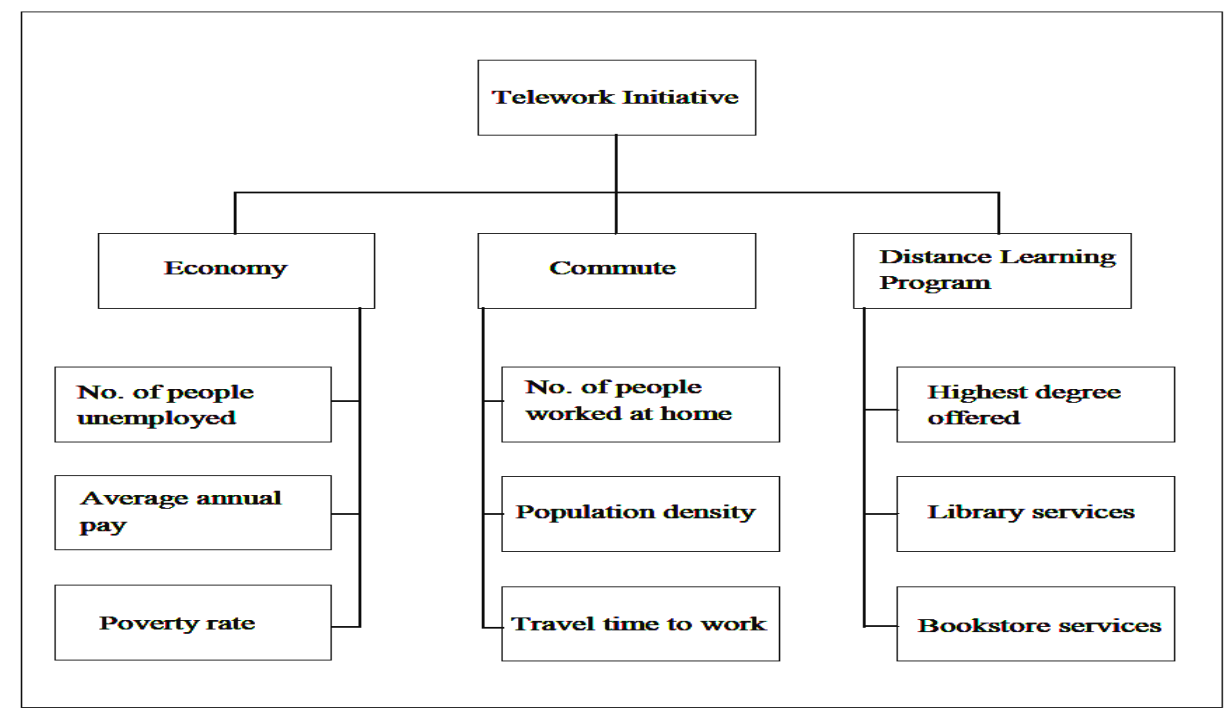

Figure 1. Catalyst of telework initiative - Gilyot et al (2004, p. 5)

\subsection{Overview of Research Method}

\subsubsection{Action Research}

An important aspect of research is determining the research methodology on discovering answers for the research problems. Through a literature review process, information about action research was gathered. Rapoport (1970) in his paper "Three Dilemmas in Action Research" defined the most commonly used definition of action research which is:

"Action research aims to contribute both to the practical concerns of people in an immediate problematic situation and to the goals of social science by joint collaboration within a mutually acceptable ethical framework." - Rapoport (1970, p. 449).

This again is in line with what was previously mentioned by Lewin (1946), whereby a research aims to address the contribution of practical knowledge towards a group of people (society) in a given situation or condition.

Lewin (1946) in his paper suggested four characteristics of action research which contributed to find answers to problems and gaining knowledge. In addition, he pointed out the importance of embracing on what he calls the "fact finding" journey. He highlighted that the "fact finding" functions as the following:

Evaluation - here he mentioned the need to evaluate the course of action which is required to be taken. This will help in determining the status a current situation (above or below average).

Learning - another function is to provide researchers with a means to gather new knowledge or insight about the topic which will facilitate the process of learning.

Planning - it also functions to assist in providing researchers on structuring steps for conducting their research.

Modification - "fact finding" also serves as a way to restructure the overall research plan to cater for knowledge 
uncovered (if any) during initial phase of the research. This provides flexibility and a much more meaningful approach to the research.

Gronhaug et al (1999) in their paper suggested a step by step set of activities which are a part of the action research framework. This frame work serves as a guideline for those who are interested with action research. It summarizes the action research process. The following diagram (Figure 2) attempt to illustrate the process flow of action research and was adapted from Gronhaug et al (1999) in their paper.

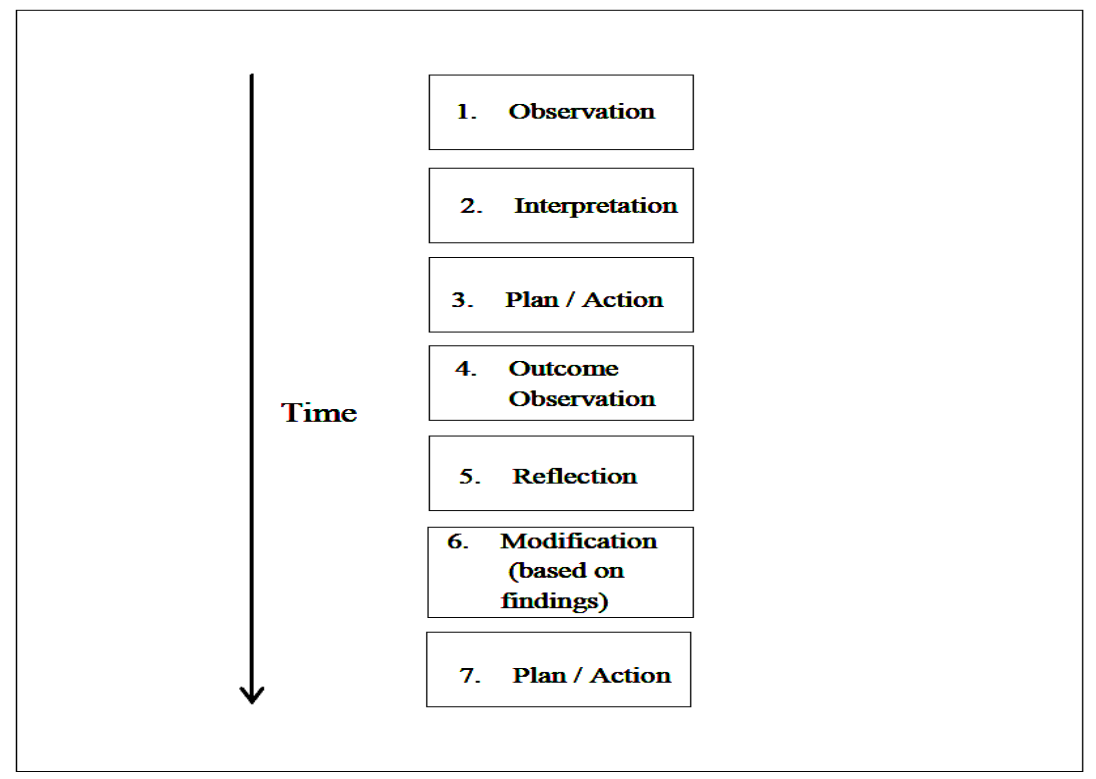

Figure 2. Action research cyclical process - Gronhaug et al (1999, p. 13)

\subsubsection{Canonical Action Research}

One of the types of action research commonly used by researchers is the Canonical Action Research (CAR). Davison, Martinsons, and Kock (2004) in their article for the "Information Systems Journal" described what CAR methodology. The term canonical is used to explain the nature of the research which is repetitive, consistent and a partnership of process oriented model. In their article they detailed the five principles of CAR, it is important to note here that these principles are merely guidelines for researchers who are keen on implementing the CAR methodology in their research. In no way are these principles mandatory framework to be followed blindly. These principles however are a useful tool in providing consistency in research results.

The first of the five principles of CAR mentioned by Davison et al (2004) is forming a collaboration agreement between researcher and client (Baskerville,1999; Argyris, 198). The second principle is the implementation of what is described by Davison et al (2004) as the "Cyclical Model". The third principal is to address the critical role of theory. The data yielded from the research should be able to address the development of theoretical knowledge to improve the circumstances of the organization. The next principle addresses the scenario specific nature of action research, by providing ability to change through action. The final principal is to ensure that the research will benefit both the researcher and the client.

\section{Research Methodology}

\subsection{Implementing Canonical Action Research}

The approach of this research is based on the canonical action research guidelines which were described in the literature reviewed. Canonical action research was chosen due to the fact that the step by step process is a much clearer approach and is mainly divided into 3 stages as demonstrated by Raman, Ryan, and Olfman (2006) in their conference paper summarizing the canonical action research approach which was implemented in his research. The steps are problem diagnosis, intervention, and evaluation (Table 1)

The usage of canonical action research is also to promote consistency in the research outcome. This is achieved through the structured approach in implementation steps of the research which will also be backed by a close collaboration between researcher and client so as to avoid any unnecessary blockage throughout the course of the research. Since any interference in the research will cause the outcome to become inconsistent this might cause 
delays and in some cases affect the accuracy of the research results.

It is understood that the methodology presented should serve as a guideline and not a mandatory set of framework. Thus, there will be some modification on the action research steps where it is deemed necessary.

Table 1. Canonical action research steps

\begin{tabular}{ll}
\hline Steps & Description \\
\hline Problem diagnosis & 1. Researcher and Client Agreement. \\
Intervention & 2. Meeting between managers to identify issues and situation. \\
& 1. Tasks identification. \\
2. Drafting of telecommuting policy. & 3. Assessment of available IT systems in the organization. \\
& 4. Identifying requirements for telecommuting. \\
& 5. Installation and configuration of communication infrastructure. \\
& 6. Installation and configuration of telecommuting infrastructure. \\
7. Knowledge transfer. & 8. Telecommuting pilot test. \\
1. Questionnaire design. & 2. Data collection. \\
3. Reflection (Data analysis). & 4. Research shortcomings and future recommendations.
\end{tabular}

\subsection{Problem Diagnosis}

\subsubsection{Researcher and Client Agreement}

The first initial step taken to kick off the research was to form an agreement between the researcher and the organization mentioned. An informal meeting was held between the researcher and the IT manager to seek consent in writing this paper with regards to the organization telecommuting project. The consent letter was submitted to seek the permission on using and collecting data about the telecommuting project from the organization.

\subsubsection{Issue Identification}

From the problem diagnostic step, the organization main issues were as follows:

1) The unavailability of business continuity management to reduce or eliminate operational disruption due to unforeseen events.

2) The lack of standardization of available remote access facility.

3) Data security with regards to the use of personal devices to access the organization's network

\subsection{Intervention}

\subsubsection{Tasks Identification}

Telecommuting is one of the approaches of business continuity management in an attempt to minimize or avoid operational disruption in unforeseen events. To kick off with the planning phase, critical operational processes (Table 2) were identified in order to identify the physical requirements of telecommuting.

Table 2. Task identification

\begin{tabular}{ll}
\hline Department & Task \\
\hline Finance & Salary payment \\
& Duty travel processing \\
& Vendor payment \\
Human Resources & Contract management \\
& Leave management \\
Procurement & Invoice processing \\
Information & Incident management \\
Technology & System administration \\
\hline
\end{tabular}




\subsubsection{Drafting of Telecommuting Policy}

To ensure that the project was in compliance with the organization operations a telecommuting policy was created as a guideline for the employees who were involved in the project. The following is the policy which was drafted and agreed upon.

1) You are only allowed to telecommute:

In case of an Emergency,

For Testing or Emergency Simulation purposes,

For other exceptional work necessities (as deemed necessary by your supervisor).

2) Only you are entitled to use the devices provided and you should use it for professional purpose only, whether in the office or at home

3) You should take reasonable and prudent care to keep your devices secure and safe at all time, by:

Locking it up in a safe place (such as a personal drawer...) should you leave the devices in the office

Locking up your screen (using CTRL-ALT-DELETE) anytime you move away from your desk, either in the office or at home

Locking it up with the provided Kensington lock anytime you move away from your desk for a meeting, lunch or any other reasons when at the office

Providing sufficient care as deemed necessary when the devices are taken out of the office

4) No personal software, program, download or documents should be installed on your laptop

\subsubsection{Assessment of IT Systems}

Analysis of the organization IT system was performed to evaluate the level of feasibility of implementing telecommuting with the available system. Based on the processes identified earlier a list of IT services considered core to the services was identified. The following is the list of mentioned core IT services:

1) Enterprise Resource Planning (ERP) System

2) Ticketing System

3) Managed Workstation

4) Network and Infrastructure Connectivity

\section{5) Communications}

\subsubsection{Telecommuting Requirements}

After identifying processes and services available, the next step was to identify requirements for telecommuting. It was also understood that one aspect of telecommuting is mobility. This means that the infrastructure which was put in place should enable employees to have mobility to perform their tasks. The following infrastructures were required to be put in place to enable telecommuting for employees:

1) Platform for applications

2) Internet connectivity

3) Organization Virtual Private Network (VPN) connectivity

\subsubsection{Installation and Configuration}

The organization utilized a central repository also known also as "software library" for applications to enable mass deployment to workstations. The solution used to manage the deployment of these applications was a software management product developed by Managesoft. The following list of applications was identified as required following the standard which was set for the workstation as well as additional applications to enable related telecommuting components. 
Table 3. Required application

\begin{tabular}{ll}
\hline Core applications & Description \\
\hline Adobe Acrobat Reader 9 & Viewer for portable document format (PDF) document output \\
Check Point Secure Socket Layer (SSL) & Plugin for VPN web client \\
Network Extender & Plugin for converting documents into PDF format \\
CutePDF & Platform for web based applications \\
& - ERP System \\
Internet Explorer 8 & - Ticketing System \\
& - VPN Client \\
Java Runtime Environment & Plugin for ERP and Ticketing System \\
Maxis Broadband Client & Mobile broadband client providing wireless internet connectivity \\
Microsoft Office 2003 Suite & Document processing (inclusive of e-mail client) \\
Skype & Voice communication tool \\
Trend Micro OfficeScan 10 & Antivirus agent \\
\hline
\end{tabular}

3.3.6 Knowledge Transfer

To accommodate the process of knowledge transfer, training material in the form of a flyer was developed. Flyer attached will be slightly edited to remove the organization's information displayed on the document. The flyer provides simple step by step guide for the employees to follow in order to use the VPN client to connect to the organization's network. During the training, the employees were guided step by step based on the material distributed. The interest shown through the question and answer session was a good indicator that the employees were keen on participating in this project.

\subsubsection{Pilot Test}

The aim of the pilot test was to identify issues related to the infrastructure of the telecommuting project. The pilot test was divided into 2 days; first day was aimed to gain feedback on the bandwidth report of the mobile broadband connection. Second day was conducted to check functionality on performing tasks through the use of the telecommuting infrastructure.

The pilot test session provided some insight on improvements needed for the telecommuting infrastructure. The following are list of changes made after the pilot test: 1. ISP evaluation, 2. Thin Client and 3. Computer Policy

\subsection{Evaluation}

\subsubsection{Questionnaire Design}

A total of 17 questions were designed aimed to gather information related to the respondents profile, knowledge sharing, organization facilitating telecommuting, data security, employees perceived benefit, organization BCM readiness, and the organization's policy.

The first part aimed to analyze the implementation of telecommuting in a non-profit organization.

Table 4. Implementation variables

\begin{tabular}{lll}
\hline Construct & Variables (Question Number) & Data Type \\
\hline Knowledge sharing & 7 and 8 & 4-Point Likert Scale \\
Organization facilitating telecommuting & 5 and 6 & 4-Point Likert Scale \\
Data security & 15 and 16 & 4-Point Likert Scale \\
Organization BCM readiness & 14 & 4-Point Likert Scale \\
Organization policy & 9 & 4-Point Likert Scale \\
\hline
\end{tabular}

The next section attempts to verify if the respondents had any perceived benefit by being part of the telecommuting project. Finally, the employees were asked if they thought that the project provided them with opportunities for professional growth

Table 5. Perceived benefit variables

\begin{tabular}{lll}
\hline Construct & Variables (Question Number) & Data Type \\
\hline Employee perceived benefits & 11,12, and 13 & 4-Point Likert Scale \\
\hline
\end{tabular}


In addition to collecting information mentioned previously, the questionnaire also collected information with regards to the profiling of the respondents

Table 6. Profile variables

\begin{tabular}{lll}
\hline Construct & Variables (Question Number) & Data Type \\
\hline Respondents Profile & $1,2,3,4,10$ and 17 & Nominal, Scale \\
\hline
\end{tabular}

3.4.2 Data Collection

Data collection was performed based on the questionnaire which was previously mentioned. The data collection was based on a selected group of 39 people. This was due to the fact that the employees selected to join this project were earlier identified based on their level of criticality. A total of 39 questionnaires were distributed among the focal points to be distributed to the selected respondents. One benefit from this survey was that it was specifically aimed to those who were relevant to the questions asked in the questionnaire. Physical print out was chosen instead of a web questionnaire. The main reason for this choice was to internal validity of the data since this research is a specific research aimed to a specific group and specific settings. It was also to ensure that the questionnaire had a $100 \%$ response rate. In addition, it was also due to the small size of the sample (39 respondents).

\section{Data Analysis}

\subsection{Reflection}

The results of the questionnaire were analyzed using descriptive statistic by describing the frequency. The method of analysis was adopted from an exploratory study of information and communications technology (ICT) and disaster preparedness in Malaysia by Magiswary (2010).

Table 7. Profile analysis

\begin{tabular}{ll}
\hline Profile & Percentage (\%) \\
\hline Age Group (Q1) & 12.8 \\
$20-29$ & 64.1 \\
$30-39$ & 20.5 \\
$40-49$ & 2.6 \\
50 and above & 100.0 \\
Total & \\
Education Level (Q2) & 15.4 \\
Diploma & 69.2 \\
Bachelor's Degree & 15.4 \\
Postgraduate Degree & 100.0 \\
Total & \\
Employment Duration (Q3) & 7.7 \\
1 year & 7.7 \\
2 years & 20.5 \\
3 years & 64.1 \\
More than 3 years & 100.0 \\
Total & \\
Technology Savvy (Q4) & 2.6 \\
Strongly Disagree & 2.6 \\
Somewhat Disagree & 35.9 \\
Somewhat Agree & 59.0 \\
Strongly Agree & 100.0 \\
Total & \\
Telecommuting Experienced (Q10) & 12.8 \\
Somewhat Disagree & 51.3 \\
Somewhat Agree & 33.3 \\
Strongly Agree &
\end{tabular}




\subsection{Implementation Analysis 1}

Table 8 .

\begin{tabular}{ll}
\hline Organization Facilitating Telecommuting & Percentage (\%) \\
\hline Sufficient Facility (Q5) & 0 \\
Strongly Disagree & 12.8 \\
Somewhat Disagree & 46.2 \\
Somewhat Agree & 41.0 \\
Strongly Agree & 100.0 \\
Total & \\
Reliable Facility (Q6) & 0.0 \\
Strongly Disagree & 15.4 \\
Somewhat Disagree & 53.8 \\
Somewhat Agree & 30.8 \\
Strongly Agree & 100.0 \\
Total &
\end{tabular}

Overall both variables scored more than $80 \%$ thus by indicating that the organization was providing proper facilities for telecommuting. To further facilitate employees additional facilities would need to be considered to be integrated with the telecommuting project. One of the things that were brought up was the integration of devices for example iPhone, Android and Windows Phone 7 to be able to access the organization network. The reasoning behind this is that it would enable employee to use their personal devices to contribute to the organization. As of the moment BlackBerry was already provided as one of the IT services for the employee.

\subsection{Implementation Analysis 2}

Table 9.

\begin{tabular}{ll}
\hline Knowledge Sharing & Percentage (\%) \\
\hline Training Effective (Q7) & 2.6 \\
Strongly Disagree & 10.3 \\
Somewhat Disagree & 56.4 \\
Somewhat Agree & 30.8 \\
Strongly Agree & 100.0 \\
Total & \\
Flyers Effective (Q8) & 5.1 \\
Strongly Disagree & 20.5 \\
Somewhat Disagree & 46.2 \\
Somewhat Agree & 28.2 \\
Strongly Agree & 100.0 \\
Total & \\
\hline
\end{tabular}

Respondents were asked if the provided training sessions were useful in familiarizing themselves with telecommuting. $56.4 \%$ somewhat agreed and $30.8 \%$ strongly agreed with the statement. $46.2 \%$ of the respondents somewhat agreed that the flyers provided were helpful. Another $28.2 \%$ strongly agreed of the effectiveness of the flyer. To further increase the training session effectiveness, training sessions should be conducted in a more frequent manner. These sessions should be used as a forum to keep the telecommuters updated with any changes and improvements of the system. Flyers should also be constantly reviewed to reflect any changes made. 
4.4 Implementation Analysis 3

Table 10.

\begin{tabular}{ll}
\hline Data Security & Percentage (\%) \\
\hline Malicious Attacks (Q15) & 76.9 \\
Never & 12.8 \\
1 Time & 0 \\
2 Times & 10.3 \\
More than 2 Times & 100.0 \\
Total & \\
Lost Notebook (Q16) & 97.4 \\
Never & 2.6 \\
1 Time & 0 \\
2 Times & 0 \\
More than 2 Times & 100.0 \\
Total & \\
\hline
\end{tabular}

The majority of the respondents (76.9\%) had never encountered any malicious attacks on their assigned notebooks. While $12.8 \%$ had encountered an attack once and $10.3 \%$ had encountered an attack more than two times. 97.4\% reported that they had never lost their assigned notebooks white $2.6 \%$ had lost it at least once.

4.5 Implementation Analysis 4

Table 11.

\begin{tabular}{ll}
\hline Organization Policy & Percentage (\%) \\
\hline Promoting Telecommuting (Q9) & 0 \\
Strongly Disagree & 38.5 \\
Somewhat Disagree & 46.2 \\
Somewhat Agree & 15.4 \\
Strongly Agree & 100.0 \\
Total & \\
Preparation for Unforeseen Events (Q14) & 2.6 \\
Strongly Disagree & 0 \\
Somewhat Disgree & 33.3 \\
Somewhat Agree & 64.1 \\
Strongly Agree & 100.0 \\
Total &
\end{tabular}

$46.2 \%$ of the respondent highlighted that they somewhat agreed that the organization is promoting the project through the telecommuting policy. However a significant portion (38.5\%) of the respondent did not agree with the policy. The disagreement was mainly due to the fact that telecommuting was only practiced as a method of working in emergency period. One of the future improvements would be to revise the telecommuting policy to enable it to be more flexible not just as a measure for emergencies.

Meanwhile, 64.1\% were in strong agreement that the telecommuting project was good in preparation for unforeseen events. This indicated that currently the facilities, policies and processes are all in place for telecommuting to act as business continuity management process. The finding is also in accordance with the feedback which stated facilities provided were sufficient $(87.2 \%)$ and reliable $(83.8 \%)$.

In the section of perceived benefit analysis, following result collected: 
Table 12.

\begin{tabular}{ll}
\hline Perceived Benefits & Percentage (\%) \\
\hline Cost Saving (Q11) & 5.1 \\
Strongly Disagree & 15.4 \\
Somewhat Disagree & 28.2 \\
Somewhat Agree & 51.3 \\
Strongly Agree & 100.0 \\
Total & \\
Time Saving (Q12) & 7.7 \\
Strongly Disagree & 15.4 \\
Somewhat Disagree & 35.9 \\
Somewhat Agree & 41.0 \\
Strongly Agree & 100.0 \\
Total & \\
Professional Growth (Q13) & 5.1 \\
Strongly Disagree & 23.1 \\
Somewhat Disagree & 53.8 \\
Somewhat Agree & 17.9 \\
Strongly Agree & 100.0 \\
Total & \\
\hline
\end{tabular}

$51.3 \%$ and $28.2 \%$ strongly agreed or somewhat agreed that the telecommuting project provided them significant cost savings as a result of not having to travel to the office. In addition, $41 \%$ and $35.9 \%$ strongly agreed or somewhat agreed that telecommuting provided them with time saving due to the removal of the requirement to travel to the office.

Yet, only $17.9 \%$ strongly agree that telecommuting provided them with opportunity for professional growth.

As part of improving the perceived benefit of employees towards the project, it is essential to make some changes in the telecommuting policy to further motivate employees. Example of changes that could be investigated is implementing are on having working day rotations where employees alternate between working out of the office and in the office or even making it a normal practice.

\section{Conclusion}

This paper provided practical implications by providing a step by step implementation guideline for the implementation of telecommuting. To the best knowledge of the researcher there were no published study has so far documented step by step process for the implementation of telecommuting. Canonical Action Research (CAR) proved to be an essential tool for this study as a result of the practical and contextual nature of the study. The use of CAR provided a way to systematically plan, implement and document projects. One of the benefits of documenting a project is it serves as future reference for other project implementation where structure and lessons learned from previous implementation will assist in future implementation of other projects. It provided a framework to guide the researcher through the whole process of the research. This involved problem diagnosis, where the research problem was identified. Then the intervention phase where the whole process of planning and implementation of plan. Finally, on evaluation step the outcome of the implementation were analyzed and reflected upon. This paper provided a starting point for the continuous nature of action research. Moreover, the study was done on a non-profit environment context which provided an insight of the attitude of the non-profit sector employees. The study carefully documented the whole process in a detailed manner. Description of variables involved in the process was provided. The implementation variable was analyzed to examine the level of BCM preparedness of the organization post implementation. Perceived benefits variable were analyzed to identify the employees acceptance towards the project. Profiling of the employees was also done through the analysis of the profile variables. Descriptive measurement of the variables conducted in effort to fulfill the research objective. 


\section{References}

Argyris, C. (1983). Action science and intervention. The Journal of Applied Behavioral Science, 19(2), 115-140. http://dx.doi.org/10.1177/002188638301900204

Baskerville, R. L. (1999). Investigating Information Systems with Action Research. Communications of the Association for Information Systems, 2(19), 1-20.

BBC NEWS. (2001, September 11). US rocked by terror attacks. Retrieved from http://news.bbc.co.uk/2/hi/americas/1537469.stm

BBC NEWS. (2008, July 8). London Attacks. Retrieved from http://news.bbc.co.uk/2/hi/uk_news/england/london/5046346.stm

BBC NEWS. (2010, January 13). Haiti devastated by massive earthquake. Retrieved from http://news.bbc.co.uk/2/hi/8455629.stm

BBC NEWS. (2011, February 30). The 2009 swine flu pandemic. Retrieved from http://www.bbc.co.uk/health/physical_health/conditions/swineflumulti1.shtml

Calder, B. J., Phillips, L. W., \& Tybout, A. M. (1981, September). Designing research for application. Journal of Consumer Research, 8, 197-207. http://dx.doi.org/10.1086/208856

Clear, F., \& Lee-Kelley, L. (2005). Risk to Data Security for Small Firms Raised by Telework. IACIS Pacific 2005 Conference Proceedings.

Davison, R. M., Martinsons, M. G., \& Kock, N. (2004). Principles of canonical action research. Information Systems Journal, (14), 65-86. http://dx.doi.org/10.1111/j.1365-2575.2004.00162.x

Garms, S. (2007, November). Telework in North America. International Telework Symposium.

Gilyot, B. T., Zhang, W., Alijani G. S., \& Thangada, D. (2004). Decision Support System: A Study of Telework Initiatives. Proc ISECON handout.

Gronhaug, K., \& Olson, O. (1999). Action research and knowledge creation: merits and challenges. Qualitative Market Research: An International Journal, 2(1), 6-14. http://dx.doi.org/10.1108/13522759910251891

Jennifer Mears. (2007, May 15). Father of telecommuting Jack Nilles says security, managing remote workers remain big hurdles. Retrieved from http://www.networkworld.com/news/2007/051507-telecommuting-nilles-security.html

Lester Kong. (2009, June 21). A (H1N1): First school in Malaysia closed (Update 2). Retrieved from http://thestar.com.my/news/story.asp?file=/2009/6/21/nation/20090621100355\&sec=nation

Lewin, K. (1946). Action research and minority problems. Journal of Social Issues, 2(4), 34-46. http://dx.doi.org/10.1111/j.1540-4560.1946.tb02295.x

Magiswary, D. (2010). ICT and Disaster Preparedness in Malaysia: An Exploratory Study. WSEAS Transactions on Information Science and Applications, 5(5), 735-748.

Raman, M., Ryan, T., \& Olfman, L. (2006). Knowledge Management System for Emergency Preparedness: An Action Research Study. 39th International Conference on System Sciences, Hawaii.

Rapoport, R. (1970). Three Dilemmas of Action Research. Human Relations, 23(6), 499-513. http://dx.doi.org/10.1177/001872677002300601

Siemens. (2009, February). White Paper: Get Lean and Green Fast with Telecommuting.

The Business Continuity Institute. (2010). Good Practice Guidelines.

Tim Clark. (2010, January 7). Eurostar train breaks down in Channel Tunnel as snow causes travel chaos across UK. Retrieved from http://www.dailymail.co.uk/travel/article-1241297/UK-weather-Eurostar-train-breaks-Channel-Tunnel-sno w-causes-travel-chaos-UK.html

Webopedia. (2011, January 28). Definition of Telecommuting. Retrieved from http://www.webopedia.com/TERM/T/telecommuting.html

Woodman, P. (2007). Business Continuity Management, Business Management Institute. British Standards Institution's Code of Practice for Business Continuity Management. 